\title{
Ethnologies
}

\section{André Petitat (dir.). Être en société. Le lien social à l'épreuve des cultures. (Québec, Les Presses de l’Université Laval, 2010. Pp. 289. Coll. « Sociologie contemporaine " ISBN : 978-2-7637-9064-0).}

\section{Marie Pier Corneau}

Volume 33, numéro 2, 2011

URI : https://id.erudit.org/iderudit/1015036ar

DOI : https://doi.org/10.7202/1015036ar

Aller au sommaire du numéro

Éditeur(s)

Association Canadienne d'Ethnologie et de Folklore

ISSN

1481-5974 (imprimé)

1708-0401 (numérique)

Découvrir la revue

Citer ce compte rendu

Corneau, M. (2011). Compte rendu de [André Petitat (dir.). Être en société. Le lien social à l'épreuve des cultures. (Québec, Les Presses de l'Université Laval, 2010. Pp. 289. Coll. « Sociologie contemporaine » ISBN : 978-2-7637-9064-0).]

Ethnologies, 33(2), 256-260. https://doi.org/10.7202/1015036ar d'utilisation que vous pouvez consulter en ligne. 


\section{André Petitat (dir.). Être en société. Le lien social à l'épreuve des cultures}

(Québec, Les Presses de I'Université Laval, 2010. Pp. 289. Coll. "Sociologie contemporaine " ISBN : 978-27637-9064-0).

\section{Marie Pier Corneau Université Laval}

Publié par les Presses de l'Université Laval en 2010, l'ouvrage Être en société. Le lien social à l'épreuve des cultures est le fruit du $18^{\mathrm{e}}$ congrès de l'Association internationale des sociologues de langue française (AISLF), qui s'est déroulé à Istanbul en 2008. Dirigé par André Petitat, professeur à l'Université de Lausanne et président de l'AISLF, il regroupe 15 conférenciers, pour la majorité des sociologues qui se questionnent et se positionnent sur des thèmes importants reliés au lien social en explorant différents domaines d'implication de l'individu aux plans personnel et sociétal.

Tous les chercheurs regroupés dans cet ouvrage ont comme point de départ cette question : "Vivons-nous une période de transition vers des sociétés qui puisent l'essentiel de leur sens et de leurs tensions dans les différences et les conflits culturels plutôt que dans les inégalités sociales et économiques? "Alors que certains parlent de "clash des civilisations " ou encore de "nouveau paradigme culturel ", d'autres insistent sur la diversification du lien social pour expliquer nombre de transformations qui s'animent à l'échelle mondiale. Orientés vers trois volets (la fragmentation de nos modes d'existence, les nouveaux rapports du culturel et du social, l'émergence de nouvelles régulations), les chercheurs présentent différentes formes du lien social à travers des problématiques diverses qui englobent plusieurs aspects : économie, politique, culture, valeurs, etc. À partir de cette interrogation principale et de ces trois volets, les chercheurs s'interrogent sur les conséquences d'un monde opaque, pluriculturel et en constant changement dans la mesure où ces transformations influencent la définition même de certains des concepts les plus solidement ancrés, comme le lien social.

La première partie, Fin $d u$ social, crise $d u$ politique, aborde notamment les effets de la mondialisation et de l'exposition des 
cultures à l'échelle mondiale. Alors qu'Alain Touraine prétend que la diffusion culturelle supplante les liens économiques, Eugène Enriquez et Vincent de Gaulejac repèrent de profondes dichotomies entre des phénomènes modernes tels que la mondialisation et l'effet sur l'individu. Par exemple, le repli identitaire et la compétition sont valorisés au détriment des valeurs communes. L'individu hypermoderne (de Gaulejac) devient un paradoxe dans un univers où il doit être conforme et, inversement, singulier et compétitif. Saskia Sassen clôt cette partie en abordant de nouveaux types de territorialité qui déstabilisent la notion même de territoire. Par-delà l'aspect géographique, les frontières sont maintenant établies en fonction des marchés et de l'économie et cela complique grandement les implications sociales et légales des sujets qui y participent.

La deuxième partie, Enchevêtrement du social et du politique, explore différentes manifestations qui peuvent être qualifiées de "sociales", mais qui possèdent tout de même des caractéristiques politiques. Cette partie est la plus chargée du recueil et elle aborde plusieurs thèmes qui semblent diamétralement opposés, mais qui se regroupent autour des actions et perceptions de différents groupes.

Michel Wierviorka a réfléchi dans sa contribution à la notion de diversité, notion qu'il qualifie de "paradoxale » considérant l'usage que chacun en fait. Tantôt utilisé pour la reconnaissance consensuelle, tantôt perçu comme une stratégie politique, le terme est souvent galvaudé selon les intentions de ceux qui l'utilisent.

Abdellah Hammoudi apporte, quant à lui, une réflexion intéressante sur les thèmes de la culture et de la violence. Le suicide, condamné dans la religion islamique, prend une signification différente lorsqu'il s'agit du jihad. L'ultime sacrifice ou le don, perçu comme une forme de violence archaïque lorsque le chercheur compare le christianisme et l'islam, s'explique et se valide dans la motivation culturelle. Cette motivation réside dans la perception et la place du sacrifice dans les croyances islamiques, par exemple le sacrifice d'Ismail, qui constitue une référence. Hammoudi tente un détachement afin de mieux cerner les thèmes du sacrifice et de la violence en essayant d'éviter les chemins empruntés par ses prédécesseurs et en laissant de côté les discours de réflexions stéréotypées. 
Joseph Tonda aborde un sujet inusité : la place du social et de la culture dans le domaine de la pensée symbolique. Il prend l'exemple du Gabon, où les médias associent le quotidien aux esprits comme si ces derniers faisaient partie intégrante de la banalité du réel. La dimension culturelle doublée de la culture symbolique est davantage axée sur les schèmes de la mort et empiète sur l'espace du social. Tonda attribue le mélange de l'espace social et culturel à un contexte sociohistorique où s'entremêlent la culture locale et globale.

Lucia Rabello de Castro apporte une riche contribution à l'ouvrage en abordant un sujet dont les conséquences sont encore aujourd'hui incertaines. Elle aborde les mouvements de la jeunesse brésilienne issus des transformations sociales et elle évalue l'influence de ceux-ci sur leurs valeurs et pratiques. À une époque où les sociétés s'influencent et où la culture devient planétaire, la jeunesse brésilienne tente de s'affilier à de nouveaux idéaux afin de s'intégrer dans les différents domaines de la société. Les jeunes mettent de l'avant les problèmes reliés à l'exclusion et tentent de revaloriser les identités à travers ces mouvements.

La dernière contribution de cette partie est apportée par Irène Théry et porte sur les enjeux d'une approche relationnelle des genres. Elle propose une approche différente de celle largement répandue sur le concept. Fréquemment utilisé comme une caractéristique identitaire, le genre est ici plutôt abordé comme une modalité des relations sociales. Le genre, comme caractéristique, est remis en cause en raison de l'influence de la culture sur les rôles et relations attendus. L'auteure met l'accent sur le " ressenti » de l'identité du genre et non sur les comportements sociaux qui lui sont attribués.

La troisième partie, Communautés, sociétés, régulations, regroupe les textes de deux collaborateurs qui abordent les tensions entre le communautarisme et l'universalisme. D'abord, Michel Seymour s'appuie sur la doctrine du libéralisme et tente de concilier celleci avec le communautarisme. Le libéralisme tel que proposé par l'auteur met de l'avant une contradiction assez importante avec le communautarisme : le vouloir-vivre collectif. Ce dernier est davantage présent dans le libéralisme politique et insiste sur la conscience nationale qui, contrairement au communautarisme, ne favorise pas le repli sur des bases culturelles comme la langue ou la religion 
au sein d'une nation. Aussi, en plus de répondre aux objections philosophiques à la reconnaissance des peuples, Seymour établit une liste en faveur de l'institutionnalisation des droits collectifs en se basant sur des conventions.

Sandro Cattacin, quant à lui, s'aventure à contre-courant des travaux réalisés par l'École de Chicago sur la question des quartiers ségrégués. L'auteur apporte une opinion nouvelle sur l'utilité de ces quartiers urbains, notamment en ce qui concerne l'identité culturelle. Cattacin s'appuie sur trois arguments qui, en somme, postulent que ces quartiers sont une opportunité puisqu'ils possèdent une utilité matérielle et symbolique en plus de représenter un lieu de stabilité identitaire et, finalement, d'être des endroits où naissent des initiatives communautaires d'entraide. Bref, l'auteur défend l'idée que ces quartiers, même s'ils sont caractérisés par des inégalités socioéconomiques, possèdent des qualités d'autorégulation. Ce type de réflexions amène à revoir le rôle de la Ville envers ses quartiers parfois délaissés et à démontrer la pertinence d'une initiative de revitalisation.

La quatrième partie est davantage axée sur la Turquie et son entrée dans l'Union européenne. Dans le premier texte, Ilber Ortayli retrace l'histoire de l'Empire ottoman en insistant sur les règles qui régissaient l'État et la romanisation qui a commencé au XIX ${ }^{\mathrm{e}}$ siècle. Cette mise au point historique s'impose puisque l'auteur enchaîne avec les réformes qui ont entraîné la laïcité limitée aux derniers siècles. Ortayli mentionne plusieurs changements sociaux à l'échelle de l'État qui ont eu pour conséquence de modifier les influences des lois religieuses dans les domaines juridique et social et qui ont été marqués par les processus de romanisation et de laïcisation.

Ivaylo Ditchev, pour sa part, aborde des thèmes plus contemporains en lien avec la situation actuelle de la Turquie au sein de l'Europe. Le parcours historique de cette région européenne ne s'est pas fait sans heurts et a eu une influence considérable sur ceux qui l'entouraient. C'est pourquoi Ditchev positionne l'émotion comme thème central de son analyse. Il qualifie ces émotions comme un jugement par rapport à la situation vécue. La passion et l'émotion sont placées à l'avant-plan pour qualifier les récents conflits. Ces émotions, à l'ère 
de la mondialisation, touchent l'identité et alimentent les craintes sur plusieurs plans, la mort et la sexualité, notamment.

La cinquième partie sert, en quelque sorte, de conclusion à l'ouvrage, où deux auteurs tentent un retour réflexif et un bilan critique sur les conférences plénières du congrès de l'AISLF. Paul Bernard reprend le thème des inégalités socioéconomiques et affirme que, malgré les efforts, celles-ci continuent d'être présentes et de structurer l'individu. Il conclut à un enchevêtrement des liens sociaux en plus d'observer une multiplicité des partenaires impliqués, qui compliquent davantage la question sociale. Claude Javeau, pour sa part, reprend différents thèmes abordés lors du congrès en attribuant au lien social deux moments distincts, institutionnel selon Durkheim et situationnel au sens de Goffman. À l'aide de ces aspects, il aborde le lien social et l'identité à travers des institutions, la langue, la famille, le droit, la position sociale, etc., et les situations qui peuvent exprimer des conflits ou des connivences qui se modulent en fonction des âges, des genres, des professions et des ethnies.

Cet ouvrage fait état de questionnements et de pistes concernant une époque, en l'occurrence le contemporain, où plusieurs phénomènes se renouvellent et changent sous l'influence de la mondialisation. Il s'avère un précieux outil pour approfondir la question du lien social sous différents points de vue et analyses. Les auteurs, bien que rattachés à la sociologie, démontrent un réel intérêt pour les autres disciplines en conciliant plusieurs des types de sciences humaines et sociales afin de faire comprendre leurs analyses. Le travail des auteurs lors de ce congrès démontre qu'une approche pluridisciplinaire devient nécessaire afin de résoudre des problèmes, ou du moins des phénomènes, nouveaux et symptomatiques de notre époque. L'ouvrage, en plus d'être complet, offre l'occasion de pouvoir s'enquérir sur la question du lien social selon différents aspects que ce dernier englobe, notamment l'économie, l'appartenance et l'identité, les migrations et les influences culturelles. 